\title{
Türk Şiirinde Gelenekten Moderne Dağ İmgesinin Değişimi: İsmail Safa - Hâlid Örneği
}

Birol BULUT'

\begin{abstract}
Öz
Türk edebiyatının takribî 1850'li yıllardan sonra değişim sürecine girdiği kabul edilmektedir. Sürecin temelini klasik şiirin duygu, düşünce ve hayal dünyasının yerine modern olanın ikâme edilmesi çalışmaları oluşturur. Bu dönüşümün kendi içerisinde sancılı olduğu gerçeği de karşımızda durmaktadır. Döneme bakıldığı zaman edebî metinlerdeki değişim dönemin ruhuna uygun olarak gerçeklik ve bunun yanı sıra görsellik üzerinden kendini ifade eder. Bu aynı zamanda dünya görüşünün ve zihnî yapının da başkalaşımı anlamını taşımaktadır. Edebiyat-ı cedide olarak karşımıza çıkan bu atılımın izlerini, klasik edebiyattan kendini ayıran hususları inceleyebileceğimiz mecralardan biri de imgelerdir. Söz konusu çalışmada yeni edebiyat cihetinde şiirler yazan İsmail Safa'nın “Dağlara” başlıklı şiiri ile klasik şiir cenâhında eser veren Hâlid’in, İsmail Safa'nın zikredilen şiirine yazdığı nazireden yola çıkarak dağ imgesinin her iki şairdeki kullanımını verip karşılaştırmasını yapmaya çalışacağız.
\end{abstract}

Anahtar kelimeler: Modern Türk Şiiri, İsmail Safa, Hâlid, İmge, Dağ

\section{The Change of Mountain Image from Classical to Modern in Turkish Poetry-The Example of Hâlid and İsmail Safa}

\begin{abstract}
Turkish Literature is accepted to have begun to change in 1850s. It changes with the use of what is modern instead of emotion, idea, and imagination within poetry. It is a fact that this transition is a troublesome process. In accordance with the era, the change in literary works is reflected through reality and visuality. This also means that worldviews and mentalities are changing. One of the points where we can study the differentiation of classical literature from this emerging movement, which is known as 'new literature',is images. This paper studies how the image of mountain is used in the poem named "Dağlara" by İsmail Safa, who is in the New Literature camp, and in the poem written by Classical Literature poet Hâlid in parallel to Safa's work.
\end{abstract}

Key words: Modern Turkish Poetry, İsmail Safa, Hâlid, Image, Mountain.

\section{Giriş}

İnsanoğlu varlığından itibaren bilincinde farklı bir kategoride kodladığı tabiata hürmet göstermiştir. Bunun sebepleri arasında tabiatın insanın kendinden bağımsız olarak hatta kendini çevreleyen bir yapıya tekabül etmesi, sürekli oluşum ve başkalaşım içinde olması gösterilebilir. Özellikle ilkçăglarda insanın tabiatla kurduğu pragmatik ilişkiyi bir kenara bırakacak olursak tabiatın kendine has sırrının insanoğlunun zihninde bir yere oturtulmamış olması onu efsunlu hâle getirmiş; dış âlem böylelikle beşeriyetin maddi ve manevî sistemlerini etkilemiştir. Tabiatın verili öğeleri arasında bulunan dağlar da eski çağlardan itibaren hemen hemen bütün medeniyetlerde kudretli bir varlık olarak algılanmış ve ona

Dr. Ö̆̆g. Üyesi, Kırklareli Üniversitesi, Fen Edebiyat Fakültesi, Türk Dili ve Edebiyatı Bölümü, birollbulutt@gmail.com [Makale kaylt tarihi: 27.6.2018-kabul tarihi: 15.8.2018] 
kutsiyet atfedilmiştir. Öyle ki Yunanlıların Olympos, Hintlilerin Meru, Japonların Fuji, Türklerin ise Tanrı Dağları başta olmak üzere birçok dağı kutsaması örnek gösterilebilir. Tabiidir ki sanat da bu durumdan nasibini almış, tabiat estetik hazzın peşinde olan sanatçının başlangıç noktası olmuştur.

Klasik şiirde dağ imgesi genel itibariyle biçimsel vasıfları etrafında benzeyen ve benzetilen olarak kullanılır. Kaynağını folklorik, mitolojik, dinî metinlerde ve İslâm tarihinde geçen özel dağ isimlerinden alır. Şairler genelde dağ kelimesi yerine sözcüğün Farsça karşıllğı "kûh", "kuhsâr", Arapça karşılı̆̆ olarak da tekil şekliyle "cebel", çoğul şekliyle "cibâl” kelimelerini tercih ederler. Eserlerde sıklıkla kullanılan özel dağ isimleri: Tûr dağı, Cebel-i Nûr, Arafât, Cudî, Merve ve Safa tepeleri, Kafdağı, Elbruz, Bîsütûn dağıdır. Aslında menkıbelerin, hikâyelerin, kıssaların mekânları arasında yer edinen meşhur dağların idealize edilmiş biçimlerinin dışında dağ imgesinin şiirde de kullanımının sınırlı olduğunu söyleyebiliriz. Bu durumun sebepleri arasında şairin maharet gösterme biçimi olarak söz sanatları içerisinde dağın, şeklî özellikleri bakımından benzetme alanının, nüansının, anlam bağlantısının mahdûd oluşuna bağlanabilir (Çavuşoğlu, 1986: 4). Ayrıca aşk'ın biçimlerini soyut bir düzlemde yakalamaya çalışan divan şairi için dağ bir güzellik formu da değildir. Dağ, güzelden ziyade ilâhî yüceliğin temsili ve tabiatın bir parçasıdır (Pala, 1989: 64).

Klasik şiirde dağ, tanrısallık bağlamında soyut bir yücelik değeri taşırken modern şiirde ise görselliğinden doğan duyguların dışavurumunu ifade eder. Dolayısıyla her iki şiir anlayışında imgenin kullanım ve işleniş biçimleri de farklılık gösterir. Divan şairi, genel olarak geleneğin kaideleri içerisinde ele aldığı mazmunu üstatları gibi işlemeye çalışırken bunu zihinselliğinin gereği olarak yapar. Çünkü "Tabiata bakmaya ve kendi intibainı tesbite ihtiyaç yoktur. Çünkü daha evvel gelen şairler bu tasviri yapmışlar ve klâsik bir örnek bırakmışlardır. Yapılacak iş, bu kelimelerin yerini değiştirerek aynı mazmunu tekrar etmektir.” (Levend, 1984: 567). Abdülkadir Karahan (1980: 55) ise, divan şairinin “(...) âdeta değişmeyen, statik, muayyen, müphem ve mecazlarla beslenen mücerret bir tabiatı terennüm et[tiğini].” söyleyerek tabiatın alegorik bir biçimde işlendiğini belirtir. Yani tabiat ve nesneleri donuk bir şekilde ele alınması bakımından minyatürlerdeki boyutsuz tasvirlere benzer. Tanpınar'ın da (2003: 3) ifade ettiği gibi eski şiir “(...) baştan aşağı kelime zevkinin idare et[tiği]” estetik görüşe sahiptir ve kelimeler ilâhî anlamı barındıran sembolik bir dile sahip olduğu için durağan üslûbun dışına çıkamaz.

Türk edebiyatında klasik şiir ile modern şiir arasında farklılıklar ortaya konurken yapılan genel geçer tanımlardan biri özellikle Tanzimat II. neslinin ve bu dönem sonrası eser veren şairlerin tabiat temini kullanması ve bu etkinin de romantizmden kaynaklandığıdır. Bu etkiyi ve farklılı̆̆ı dağ imgesi üzerinden İsmail Safa'nın "Dağlara" başlıklı şiiri ile klasik tarzda eser veren ve İsmail Safa'nın zikredilen şiirine nazire yazan Hâlid'in gazeli etrafında göstermeye çalışacağız. Çalışmaya konu olan iki şiirin tam metni aşă̆ıdaki gibidir: 


\section{Dağlara}

Mün'akisdir kalbimin hüzn ü melâli dağlara Ebr-i ‘ulvî manzarın düşmüş zılâli dağlara

Dûş ber dûş teselsül, ser-be ebr-i i'tilâ Gözlerim bakmakla doymaz böyle âlli dağlara

Dinledi feryâdımı dağlarla taşlar inledi Yer gök oldu peyrev efgânımla mâli dağlara

Sence imkân-ı tesir yok mudur ey senin dil? Âhımın varken dokunmak ihtimâli dağlara!

Şiddet-i sevdâ ile cennet getirdim gâlibâ: Ben de düşdüm ‘âkıbet Mecnûn misâli dağlara!

Hem zebânımdır benim karşımda her taş, her kaya Şimdi hasr ettim demektir hasbihâli dağlara

Sorduğum șeyi yine benden sorarlar 'aksine Eylesem îrẩd herhangi suâli dağlara

Olmasaydı 'aşk u volkanlar zuhûr etmez idi Âh! Bağrım yandı çok göremem bu hâli dağlara!

Olmasa dağlarda bir mazmûn-ı ulvî mündemiç Meyl eder mi şâirin fikr ü hayâli dağlara?

Her hayâl-i şâirânem dağların mahsûlüdür Pür-maâlî dense lâyıktır şu hâli dağlara

Hayli şeyler söyledim sahrâlara, vâdîlere Hayli şeyler söyledim ben lâubâli dağlara

Dağların ulviyeti efkârımı i'lâ eder

Eylerim şiirimle ibrâz-ı maâli dağlara

Dağ başında ey Safâ bir feyz-i cûş-â-cûş ile Bir gazel yazdım ki aittir meali dağlara

$$
\text { (İsmail Safa, 1308: 147-148). }
$$

\section{Şâ'ir-i Meşhur İsmâil Safâ Bey'e Naziresidir}

Çünki meyl-i tab'ımın var iștimâli dağlara Kenz-i dilden eylerim nesr-i leâlî dağlara

Vech-i her zerre tecelligâh-ı zevk-ı cândır Hâs değildir nûr-ı vech-i zü’l-celâli dağlara

Gerçi her zerre hakikat nurunun bir tavrıdır Lîk Hakkın düştü mîkât-ı visâli dağlara

Her nazarda başka bir manâ-yı ulvî berk urur Ayn-ı hikmet-bînin olsa ittisâlı dağlara

Bir hazîn dîdâr-ı hikmet hayra bahş-ı cân olur Zîb olunca kudretin bedr ü hilâli dağlara

Eyledin Hâlid Safâ-yı dil ile arz-ı vefâ

Tab'-ı Nâci eylemez mi meyl-i âlî dağlara

\section{Hâlid}

(Ahmed Bâdi Efendi, 2014: 1716).

İsmail Safa'nın Fi Şubat 1305 (1890) tarihinde tamamladığı şiir döneminde işlediği konu ve üslup bakımında meşhur olmuş, birçok şairin teveccühünü kazanmış ve şiire birçok nazire yazılmıştır². Yazılan nazirelere bakıldığı zaman bunlardan sadece Hâlid’in metninin farklılığı göz çarpar. Bu nazire bir nevi karşı-poetikadır. İsmail Safa'nın³ konuyu ele alış biçimine, öne çıkardığı duygulara karşı Hâlid4 aynı

2 Örneğin Abbâs Hâverî "Gazel” başlı̆̆ı ile yazdığı "Dağlara” redifli şiiri için şu notu düşer: "Şâir-i mâderzâd İsmail Safâ Bey”in gazel-i meşhuruna naziredir.” (Abbâs Hâverî, 1311: 14).

3 Asıl şöhretini Servet-i Fünûn döneminde yakalayan ve Edebiyat-ı Cedide saflarında yer alan İsmail Safa 21 Mart 1867 tarihinde Mekke'de dünyaya gelir. Yedi yașında iken annesini, on üç yaşında iken babasını kaybeder. Babası M. Behçet Efendi’nin ölümü üzerine kardeşleri ile birlikte 1878 tarihinde İstanbul'a gelen İsmail Safa, Dârişşafaka'ya kaydolur. 1887 tarihinden itibaren memuriyete atanır. Bu yıllarda edebî çevrelerde de tanınmaya başlar. Siyasî sebeplerden dolayı 1900 yllında Sivas'a sürgün edilir. 24 Mart 1901 tarihinde ise Sivas'ta vefat eder. Daha geniş bilgi için bkz: Alâattin Karaca, İsmail Safa, Kültür Bakanlı̆̆ Yayınları, Ankara 1990.

4 Asıl adı Hasan Hâlid Efendi'dir. 1262 tarihinde Eyüp'te dünyaya gelir. 1281 tarihinden itibaren cesitli devlet memuriyetlerinde bulunur. 1296 tarihinde Edirne’ye gelerek Erkân-ı Harbiye nezaretinde şube müdürlügünde bulunur. 25 Eylül 1906 tarihinde Edirne'de vefat eder. Kendisi Mevlevidir ve Edirne Mevlevîhânesinde vaazlar vermiştir. Sultan Veled'in "Aşknâme” adlı eserinin yirmi üç beytini sserh etmiştir. İbnü’l-Emin Mahmud Kemal İnal, Hâlid için şu yorumu yapar: “Münevver, natuk, müeddeb, tekellüften âzâde bir zât idi.” Geniş bilgi için bkz: İbnü’l-Emin Mahmud Kemal İnal, Son Asır Türk Şairleri (Kemâlü’ş-Şuara), Cilt II, Haz: M. Kayahan Özgül, Atatürk Kültür Merkezi Yayınları, Ankara 200o, 
konu ve imgeye geleneğin perspektifinden yaklaşır. İlk olarak İsmail Safa'nın şiirinde dağ imgesinin kullanımına bakalım.

İsmail Safa’nın şiirinde öncelikle "ben” ön plana çkkarılır. Bir objenin konu olarak seçilmesi, fiillerde I. tekil şahsın kullanımı ve bununla bağlantılı olarak "göz" ve "ses" ile ilgili kelimelerin seçimi dikkat çeker. Öncelikle şunu belirtmek gerekir ki şiir hâlâ form ve üslup bakımından geleneğin etkisinden tam olarak çıkabilmiş değildir. Bu noktada şiiri geleneğin çizgisinden koparan şey tabiata yönelim, tabiatın nesnesi olarak dağların algılanış biçimi ve dolayısıyla öznelliğin inkişafıdır. İlk beyitte bulutun gölgesinin dağlara düşmüş olmasının yansıttığı görüntü şair öznede hüzün ve melâl duygusuyla özdeşleşir. İkinci beyitte ise sıradağların yüceliğinin verdiği duygunun ortaya çımasını sağlayan ise gözdür.

Şiirde ilk beyitten itibaren romantizmin etkisinin olduğu görülmektedir. Bu etkinin anahtar kavramlarını şu şekilde ifade edebiliriz: tabiata, manzaraya ve kırsala verdiği önem; görsel imajla ve yüce ile bağlatışı ayrıca bunu anlatabilecek bir teknik olarak perspektiften yararlanma, melankoliden beslenmesi ve bunların toplamı olarak romantizmin modern ile olan ilişkisidir. Türk şiirinin modernleşme adına yararlandığı kaynakların başında romantizm gelir. Çünkü romantizm on dokuzuncu yüzyll Batı'sında Calinescu'nun (2013: 44) ifadesiyle “modernin eş anlamlısı" ve Paz’ın (1996: 83) ifadesiyle de "modernliğin öteki yüzü"dür. İlk iki beyti bu minvalde değerlendirecek olursak öncelikle melankolik hâl, görsel imaj ve sonsuzluk hissiyatının var olduğunu görebiliriz.

Romantiklerin eleştirdikleri ve bu yolla kendilerini meşrulaştırdıkları söylemlerden biri Aydınlanma Çağı'nın mekanik tabiat düzenine karşı çıkmaları ve tabiatı Tanrı ile içkin hâle getirerek hareketli bir yapıya büründürmeleridir. İsaiah Berlin (2004: 129) bu noktada romantiklerin tasavvur ettikleri şekilde tabiat ve insan arasındaki bağlantıyı ifade etmeye çalışırken ıstarap halinde olduğunu belirtir. Diğer bir husus ise bireyin melankolisidir. Bu tam olarak aslında benliğe tekabül eden bir durumdur. İsmail Safa daha şiirin ilk mısrasında "melâl" kelimesinin öznelliğini ve melankolik hâlini yansıtmak ister. Dikkat edilirse "melâl" ve "hüzn" kelimeleri ardarda kullanılır. Burada melâl daha çok seküler, hüzn ise manevî literatüre karşılık gelen umutsuzluk/mutsuzluk durumlarıdır. Melâl ne İslam literatüründe ne de bununla ilişkili olan klasik edebiyatta kullanılan bir kavram değildir. Çünkü içerisinde umutsuzluğu ve modernitenin insan ruhu üzerindeki yıkıcılığı ve yalnızlığını barındırır. Lakin "hüzn"de ise huzursuzluğun kaynağı ilâhîdir ve Allah'tan kopuşu ifade eder (Akay, 1995: 201). Burada şair öznenin melâlinin sebebi belirsizdir. Modernliğin merkezi olarak kentten kaçışı ve bunalımını romantik bir duyuşla yükleyeceği yer ise kırsalın en dikkat çeken görüntüsü olarak ise dağlardır:

Mün’akisdir kalbimin hüzn ü melâli dağlara

Ebr-i 'ulvi manzarın düşmüş zllâli dağlara

...

Dinledi feryâdımı dağlarla taşlar inledi

Yer gök oldu peyrev efgânımla mâli dağlara

Sence imkân-ı tesir yok mudur ey senin dil?

Ahımın varken dokunmak ihtimâli dağlara!

$\cdots$

ss. 790-791; Ahmed Bâdî Efendi, Riyâz-ı Belde-i Edirne (20. Yüzyıla Kadar Osmanlı Edirne'si), Cilt II/II, Haz: Niyazi Adıgüzel - Raşit Gündoğdu, Trakya Üniversitesi Yayını, Mayıs 2014, ss.1714-1715; Bursalı Mehmed Tâhir Bey, Osmanlı Müellifleri, C: II, Haz: A. Fikri Yavuz - İsmail Özen, Meral Yayınevi, İstanbul 1972, ss.178-179. 
Hem zebânımdır benim karşımda her taş, her kaya

Şimdi hasr ettim demektir hasbihâli dağlara

Melankoli, şairin ilham perisidir ve bu hâlin varlığını ifade ederek şiire başlar. Bulutun dağa düşen gölgesini farketmesi ile birlikte yaşadığı bunalımı görüntü ile özdeştirir. Kişileştirilen ve yerle gök arasında bağlantı noktası olan dağlar, şair öznenin melâli ve hüznü karşısında kayıtsız kalmaz. Dağlarla bunalımı arasında temas kurmak ister. Şair özne şiirde dağların görüntüsünü klasik şiirden farklı olarak ona bir nesne biçiminde yaklaşmaya çalışırken, genel itibariyle dağın yüceliği ve görüntünün oluşturduğu duygulara kapılır. Bazı mısralarda resim sanatının bir tekniği olarak gölge ve derinlik kullanılarak perspektif oluşturulmaya çalışılır:

Ebr-i ‘ulvi manzarın düşmüş zllâli dağlara

Ardından dağların sıralanışında yükseklik ve uzunluk vurgusuyla birlikte yatay ve dikey perspektif sağlanmaya çalışılır:

Dûş ber dûş-1 teselsül, serapa i’tilâ

Gözlerim bakmakla doymaz böyle ‘âli dağlara

Şair öznenin gerek melankolik hâlini dağlara yansıtma isteği gerek derinliğe ve yüksekliğe dair perspektif oluşturma çabalarının altında yatan durum şairin yüce ile ilişkisinden kaynaklanmaktadır. Çünkü "yüce”, modern sanatta imge oluşturma biçimlerinin başında gelmektedir. Bu etkinin geldiği ve Türk şairlerinin etkilediği akım ise romantizmdir. Romantizm, yaratıcı dehâyı ön plana çıkarmayı amaçlar. Yüce, dehânın -tabiat nesneleri karşısındaki- imgelemini ve duyarlılığını besleyen temel olgulardan biri hâline gelir (Bulut, 2017: 135).

Yüce, klasik sanat formları içerisinde rahmanî bir anlama tekabül etmekteydi. Aydınlanma sonrası "birey"in ortaya çıkışı ile yüce artık ilâhî manadan uzaklaşıp görselliğin ön plana alındığı ve görsel hazzın ortaya çıktığı imajlar hâlini aldı. "Bu hissiyatın temelinde kutsal alan olarak doğanın kendinden meydana getirdiği düşünülen sonsuzluk düşüncesine ulaşmanın gerçeklik üzerinden tanımlanması yatar." (Bulut, 2017: 135). Yücenin insanda bıraktığı hissiyatla ilgili literatürde ilk tanımlamalardan birini Edmund Burke yapar. Burke yüceyi tanımlamadan önce bunun ön koşulu olarak görmenin verdiği hazzı başlar. Çünkü gözle edinilen haz durağandır ve kişiden kişye değişmediği için herkes aynı duygulara kapı aralar (Burke, 2008: 20). Yücenin insanda bıraktığı duygu, acı ve tehlikenin kaynaklık ettiği korku ve dehşet; kendinden var olan görkemin bıraktığı şaşkınlıktır (Burke, 2008: 61) ve bu tarz duyguları tetiklemesi tabiatta yeni bir gerçeklik ve heyacan bulan romantiklerin estetik görüşlerini belirleyici bir hâl alır. Göz alabildiğince yüksek bir dă̆ yahut sıradağlar, bu duyguları ortaya çıkaran tabiatın verili öğeleri arasındadır. Dağların ihtişamı karşısında korku ve heyecana kapılan romantikler bu duyguyu ortaya çıkarabilme adına görme bilincini ve bu yolla tasviri kullanmaya başlarlar ki zaten romantizmin sanata getirdiği yeniliklerden birisi sanatta tedahüle salık vermesidir. Dağların görüntüsünü özümseyen ve içselleştiren sanatçıda görünütünün verdiği haz sonrasında duygularını ortaya çıkarır. "Dağlara” şairi de görmeye ve göze ayrı bir önem vererek dağların görüntüsünün kendinde meydana getirdiği hazzı ve manayı ortaya koymaya, anlamaya; dağların görüntüsünden dolayı dağlara meyl ettiğini ifade eder:

Dûş ber dûş teselsül, ser-be ebr-i i’tilâ

Gözlerim bakmakla doymaz böyle ‘âli dağlara 
Olmasa dağlarda bir mazmûn-ı ulvî mündemiç

Meyl eder mi şâirin fikr ü hayâli dağlara?

Her hayâl-i şâirânem dağların mahsûlüdür

Pür-maâlî dense lâyıktır şu hâli dağlara

Dağların ulviyeti efkârımı i’lâ eder

Eylerim şiirimle ibrâz-ı maâli dağlara

Şunu da belirtmek gerekir ki Türk edipler tabiata yönelmeyi Batılı meslektaşlarından öğrenmişlerdir ve Türk ediplerden çok azı Batılı meslektaşlarının tabiatla ilişkisi babında yaşadığı deneyimi yaşamışlardır. Tecrübe eksikliğinin sebepleri arasında akımın kendi içindeki dinamikleri Türk ediplerin sonradan öğrenmesi ve yaşanılan coğrafyadır. Gerek Tanzimat gerekse Servet-i Fünûn neslinin yaşadığı yer İstanbul'dur ve çok azı taşraya açılmıştır. Her ne kadar yedi tepe üzerine kurulmuş bir şehir olsa da İstanbul veyahut çevresinde heybetli bir dağ görmelerine imkân yoktur. Bu tecrübeyi ancak İstanbul dışına çıktıkları ve ya başka bir ülkeye gittikleri zaman yaşamışlardır. Örneğin bu tecrübeyi yaşayan isimlerden biri Abdülhâk Hâmid'in şiirlerine bakılacak olursa özellikle Hindistan'da olduğu dönemde gördüğü dağlar karşısında şaşkınlığını gizleyememiş ve durum şiirlerine de yansımıştır (Enginün, 1995: 303-306). "Dağlara" şiirinde ise şair öznenin dağlarla olan ilişkisi bir tecrübeden ziyade daha çok resim veya tablo üzerinden olması muhtemeldir. Çünkü bazı mısralarda genel geçer tasvirler yapılmakla birlikte dağlarla karşılaşma anına ve içinde bulunduğu mekâna ve konumuna dair herhangi bir ibare yoktur.

Hâlid ise yazdığı nazirede İsmail Safa'nın bilinmeyen melâlinden ziyade yaratılışından ötürü dağlara bir meylinin olduğunu ve bu sebeple dağlara şiir yazdığını ifade eder. Dağları Allah'ın kudretinin ve birliğinin bir sembolü olarak gören Hâlid, bu manayı içselleştirirken İsmail Safa'dan farklı olarak özellikle "hikmet, tecelli, hakikat" kelimelerini kullanır. Bu kullanım nesnenin kendisinden ziyade arkasındaki ilahî anlama ulaşmaya yönelik bir tasavvurdur. Şiir gerek dil, gerek üslup gerekse mana olarak klasik şiirin etrafında oluşturulur. İsmail Safa'nın şiirinde görsel imaj ve dinî manadan bağımsızlık olarak duygunun öne çıkardığı yücelikten ziyade Halid'in şiirinde idealize edilmiş ve zihinselliğin oluşturduğu ve rahmanî unsurlarla bezeli bir dağ kavramını görmekteyiz.

\section{Sonuç}

Hâlid'in naziresinde her ne kadar bir dağ ismi kullanılmamış olsa bile tecelli ve hakikat kavramlarından Tûr dağına bir gönderme yapıldığı görülmektedir. Dolayısıyla şair gördüğü, deneyimlediği bir dağı değil İslam literatüründe Allah’ın tecellisinin yansıdığı ve idealize edilmiş bir dağdan bahsetmektedir. İsmail Safa'nın dağ karşısındaki hissiyatını besleyen unsurlar melankoli ve yücelik iken Hâlid, İsmail Safa'ya karşı olarak zihnindeki dağın hiçbir şüpheye yer vermeksizin Allah’’ hatırlattığını ve dağın ihtişamının Allah'ın varlığının bir sembolü olduğunu vurgular. Her iki şairde aslında dağı araçsallaştırır. Fakat buradan çıkartıkları anlam farklıdır. İsmail Safa bireysel bir teamülle dağa yaklaşarak gördüğü yücelik karşısındaki hissiyatını anlamdırmaya çalışırken Halid'in dağ karşısındaki tutumu nettir. Çünkü ona göre dağlar Allah'ın tecelli ettiği bir mekândır ve bu manayı ancak hikmeti arayan göz görebilir. Hâlid İsmail Safa'nın aksine dağı soyut olarak ele alır. İsmail Safa, dağ imgesini romantizm bağlamında kullanarak gelenekten ayrışma yoluna gitmiş; Hâlid ise yazdığı nazirede dağ imgesi bağlamında 
geleneğin temsilcisi olmayı tercih etmiştir. Aynı imge etrafında her iki yazarın duyduğu farklıdır. Tanpınar’ın dediği gibi dönemde yaşanan ikiliğin bir resmini bize sunmuşlardır.

\section{Kaynakça}

Akay, H. (1995). İslâmi Terimler Sözlüğü̈. İstanbul: İşaret Yayınları.

Berlin, I. (2004). Romantiklğin Kökleri. (H. Hardy, Dü., \& M. Tunçay, Çev.) İstanbul: Yapı Kredi Yayınları.

Bey, B. M. (1972). Osmanl Müellifleri (Cilt II). (A. F.-İ. Özen, Dü.) İstanbul: Meral Yayınevi.

Bulut, B. (2017). Yeni Türk Şïrinde Dağ. Sakarya: Yayımlanmamış Doktora Tezi.

Burke, E. (2008). Yüce ve Güzel Kavramlarımızın Kaynağı Hakkında Felsefi Bir Soruşturma. (M. B. Gümüşbaş, Çev.) Ankara: BilgeSu Yayıncılık.

Calinescu, M. (2013). Modernliğ in Beş Yüzü (2 b.). (S. Gürses, Çev.) İstanbul: Küre Yayınları.

Çavuşoğlu, M. (1986). Divan Şiiri. Türk Dili, LII(415-416-417), 1-16.

Efendi, A. B. ( Mayıs 2014). Riyâz-ı Belde-i Edirne (2o. Yüzyıla Kadar Osmanlı Edirne'si) (I b., Cilt II/II). (N. A.-R. Gündoğdu, Dü.) Edirne: Trakya Üniversitesi Yayını.

Enginün, İ. (Dü.). (1995). Abdülhak Hâmid'in Mektupları. İstanbul: Dergâh Yayınları.

Hâverî, A. (1311). Fecr. İstanbul: Malûmât Matbaası.

İnal, İ.-E. M. (2000). Son Asır Türk Şairleri (Kemalü'ş-Şuara) (Cilt II). (M. K. Özgül, Dü.) Ankara: Atatürk Kültür Merkezi Yayınları.

Karaca, A. (1990). İsmail Safa. Ankara: Kültür Bakanlığı Yayınları.

Karahan, A. (1980). Eski Türk Edebiyatı İncelemeleri. İstanbul: İstanbul Üniversitesi Edebiyat Fakültesi Yayınları.

Levend, A. S. (1984). Divan Edebiyatı: Kelimeler ve Remizler, Mazmunlar ve Mefhumlar (4 b.). İstanbul: Enderun Kitabevi.

Pala, İ. (1989). Ansiklopedik Divân Şüri Sözlüğü (Cilt II). Ankara: Kültür Bakanlığı Yayınları.

Paz, O. (1996). Çamurdan Doğanlar (Romantizmden Avangarda Modern Şiir). (K. Atakay, Çev.) İstanbul: Can Yayınları.

Safa, İ. (1308). Huz Mâ Safâ. İstanbul: Alem Matbaası.

Tanpınar, A. H. (2003). 19'uncu Asır Türk Edebiyatı Tarihi (10 b.). İstanbul: Çağlayan Kitabevi. 